\title{
Book review: Oxford Weather and Climate since 1767 by Stephen Burt and Tim Burt
}

\author{
Karen L. Aplin \\ Department of Aerospace Engineering, University of Bristol, Bristol, UK \\ Correspondence: Karen L. Aplin (karen.aplin@bristol.ac.uk) \\ Published: 10 October 2019
}

Burt, S. and Burt, T.: Oxford Weather and Climate since 1767, Oxford University Press, Oxford, UK, 2019.

The Radcliffe Meteorological Station in Oxford is unique in the UK, and it is one of a handful of stations worldwide to have maintained continuous observations at the same site since 1815. The (unrelated) authors were inspired to prepare Oxford Weather and Climate since 1767, the first book about the station, by the bicentennial event held in 2015. Twin motivations are the lack of detailed publications about the site and its instrumentation - though shorter summaries exist, e.g. Smith (1968) - and the aim to present and summarise the full data set. This second goal is particularly laudable, as the proper treatment of climatological data is widely recognised as ever more important.

Historical data sets play a significant part in the assessment of long-term change, and numerous attempts have been made to combine sporadic and brief time series from multiple locations, perhaps most famously the Central England Temperature series (Manley, 1953). However, it does not take much detective work when searching for original source data in such compilations to realise that they are rarely completely described, thus preventing full examination. Dedicated journals now exist for the presentation and description of data (e.g. Allan, 2014), which may remedy some of these problems. In addition to being the first detailed historical account of a site of such climatological significance, Oxford Weather and Climate provides a complete description of the data values themselves.

Put simply, everything one could ever want to know about the weather and climate of Oxford in the last 250 years is in this book. Why 250 years? Until its move to South Africa early in the 20th century, Oxford's Radcliffe Observatory, started by Thomas Hornsby (1733-1810), Savilian Professor of Geometry, was used for both astronomical and meteoro- logical observations. Burt and Burt explain that Hornsby's early writings indicate his enthusiasm for meteorology, with the 1767 date in their book's title referring to the start of his regular rainfall observations, which were first made in 1761 . These ceased with his old age in 1804 and were resumed by the Observatory in 1811, with Burt and Burt establishing, in a significant historical achievement, that the first full year of records was 1814 rather than 1815 , as was previously thought. Oxford Weather and Climate since 1767 actually looks much further back than its title might suggest, including pre-Hornsby observations from the 17th century, including those by the philosopher John Locke, and even including William Merle's 14th century weather diary.

As well as extensive historical information, the book covers the contemporary site, its management by the Geography Department, and the weather and climate of Oxford within the regional and global context. The considerable urban development over the duration of the observations is considered in some detail, though it is not thought to have strongly affected the data. Much of the book is taken up with a monthby-month, and a season-by-season, summary of the data, describing averages, trends, extremes, and any particularly notable events. This aspect is a highly valuable reference source, illustrated by good-quality plots and, where possible, archive photographs. I understand the authors delayed publication in order to include the very warm (though not record-breaking, as readers of the book will learn) summer of 2018 in their discussion. In fact the data values presented extend to the end of the calendar year 2018, an impressive achievement given publication was in May 2019.

The analyses presented are rigorous and do not make statistical assumptions about the data. I did wonder if more use could have been made of statistical tests in discussions of, for example, consecutive years in which records were broken. Presumably at least some of these "coincidences" are 
to be expected from random fluctuations in such a long data series, and statistical tests might provide some quantitative support either way. Some trends are evident in the data, such as the well-known long-term warming. Discussion of temperature is slightly confusing due to the odd choice of units, with two systems used, ${ }^{\circ} \mathrm{C}$ for absolute measurements (e.g. "it is $20.4{ }^{\circ} \mathrm{C}$ ") and $\operatorname{deg} \mathrm{C}$ for a change in temperature ("this is $8.5 \mathrm{deg} C$ greater than the nocturnal minimum"). This convention is used in some meteorological journals, but remains an unnecessary complication for a quantity that is important to communicate to non-scientists, and which has a clearly defined unit (Bureau International des Poids et Mesures, 2019). Other, more unexpected, trends in the long Oxford record are a decrease in fog and an increase in rainfall. The decrease in fog and mist can be attributed to the reduction in pollution from smoke, particularly after the Clean Air Act in 1953, but the increase in rainfall with time remains to be fully explained.

Oxford Weather and Climate of course contains a full discussion of the meteorological instruments used and their deployment, both now and in the past. The appendices include monthly summaries of all the data 1813-2018 - a valuable resource, but not, as far as I could find, available online. Hopefully this situation will be remedied soon, to facilitate future analysis and avoid any transcription errors from the book to a computer. The entire book is well written in a readable and accessible style, suitable both for non-scientists and experts, whilst simultaneously providing an incredibly thorough description of the site, its data, and the historical and scientific context. The outer chapters can be read in full as a historical introduction and summary, with the inner detailed chapters perhaps best dipped into to find dates, events or meteorological quantities of interest. The authors have skilfully (and rapidly) pulled together an impressive combination of historical and scientific analyses to produce this beautifully presented, enjoyable and informative volume. It deserves to remain the definitive reference book for this iconic site and its data for many years to come.

\section{References}

Allan, R.: Geoscience data, Geoscience Data Journal, 1, 1-1, 2014. Bureau International des Poids et Mesures (BIPM): SI Brochure, 9th Edn., available at: https://www.bipm.org/en/publications/ si-brochure/, last access: 3 October 2019.

Manley, G.: The mean temperature of central England, 1698-1952, Q. J. Roy. Meteor. Soc., 79, 242-261, 1953.

Smith, C. G.: The Radcliffe Meteorological Station: One hundred and fifty years of Oxford weather records, Weather, 23, 362-367, 1968. 